\title{
Efeito da suplementação oral de l-glutamina na parede colônica de ratos submetidos à irradiação abdominal ${ }^{1}$
}

\author{
Cristina Fajardo Diestel ${ }^{2}$, Francisco Lopes-Paulo 3 , Ruy Garcia Marques 4 , \\ Nara Limeira Horst $t^{5}$, Carlos Eduardo Rodrigues Caetano ${ }^{6}$
}

\begin{abstract}
Diestel CF, Lopes-Paulo F, Marques RG, Horst NL, Caetano CER. Efeito da suplementação oral de l-glutamina na parede colônica de ratos submetidos à irradiação abdominal. Acta Cir Bras [serial on line] Available from: URL: htt://www.scielo.br/acb.

RESUMO - Objetivo: Avaliar as alterações estruturais na parede do cólon irradiado, em ratos, verificando se a suplementação de Lglutamina pode prevení-las. Métodos: Foram empregados 30 ratos Wistar, machos, adultos, divididos em três grupos: I - controle, IIirradiado e III - irradiado, com suplementação de L-glutamina durante os 14 dias do estudo. O Grupo Controle foi mantido em condições-padrão de laboratório, enquanto os grupos II e III foram submetidos à irradiação abdominal, com dose única de 1000 cGy, no $8^{\circ}$. dia da experimentação. Todos os animais foram operados no $15^{\circ}$. dia, para ressecção de segmento colônico para análise estereológica. Resultados: O grupo II apresentou volume total da parede colônica significativamente menor que o Grupo Controle, sem alterar os volumes parciais de cada camada histológica. No grupo III, houve manutenção do volume total da parede do cólon, próxima ao Grupo Controle, com aumento significativo da camada mucosa, quando comparada aos grupos I e II. Na camada mucosa do grupo III, houve a manutenção do volume parcial do epitélio, comparado ao Grupo Controle, sem melhora significativa da superfície epitelial. Conclusão: Sugere-se que a suplementação de L-glutamina seja benéfica na parede do cólon irradiado, em ratos.
\end{abstract}

DESCRITORES: L-glutamina. Irradiação abdominal. Parede colônica; Cólon; Mucosa.

\section{Introdução}

O uso da radiação ionizante exerce papel fundamental no tratamento do câncer, ao lado da cirurgia, quimioterapia e imunoterapia ${ }^{1}$. Sua meta é administrar dose tumoricida, poupando, na medida do possível, os tecidos normais, pelos quais ocorrerá a regeneração da área irradiada. No entanto, a sua utilização pode induzir o surgimento de inúmeros efeitos indesejáveis, de grau variado, no tecido sadio. Tecidos com renovação celular acelerada, como a mucosa do tubo gastrointestinal, são mais vulneráveis aos efeitos tóxicos agudos, como a enterite actínica ${ }^{2}$.

A radioterapia diminui a atividade proliferativa nas criptas, interrompendo o suprimento de células às vilosidades e diminuindo a sua espessura e a superfície absortiva da mucosa ${ }^{3}$. O íleo e o jejuno são os segmentos do tubo digestório mais susceptíveis a essas alterações, seguidos pelo cólon transverso, sigmóide e reto ${ }^{4}$. A enterite manifesta-se clinicamente por dor abdominal em cólica, diarréia e mal-absorção que, eventualmente, podem determinar a interrupção do tratamento.

A glutamina, um aminoácido neutro e gliconeogênico, é classicamente classificado como não-essencial, porém, pode se tornar indispensável em situações catabólicas, como trauma e sepse. Por essa razão, mais recentemente, diversos autores vêm considerando este aminoácido como condicionalmente essencial $^{5}$. Uma de suas principais funções é a de se comportar como combustível oxidativo para células de replicação rápida, incluindo células do trato gastrointestinal (enterócitos e colonócitos) e células imunológicas (linfócitos e macrófagos) ${ }^{6}$. Atualmente, alguns estudos têm demonstrado um efeito protetor da glutamina no intestino delgado irradiado, ${ }^{7,8}$ porém o efeito deste aminoácido no cólon irradiado, motivo deste estudo, ainda encontra-se por ser elucidado.

\section{Métodos}

Este trabalho foi realizado no Laboratório de Cirurgia Experimental da Faculdade de Ciências Médicas, no Departamento de Anatomia Humana do Instituto de Biologia Roberto Alcântara Gomes e no Setor de Radioterapia do Centro Universitário de Controle do Câncer do Hospital Universitário Pedro Ernesto - Universidade do Estado do Rio de Janeiro.

Utilizou-se um modelo experimental com ratos submetidos à irradiação do abdome, com ou sem a suplementação oral com L-glutamina. Realizou-se análise estereológica em que foram avaliados o volume total e os volumes parciais de cada camada da parede colônica, bem como os volumes parciais do epitélio e da lâmina própria da mucosa.

\footnotetext{
1. Trabalho realizado no Laboratório de Cirurgia Experimental - Faculdade de Ciências Médicas, no Departamento de Anatomia Humana Instituto de Biologia Roberto Alcântara Gomes e no Setor de Radioterapia do Centro Universitário de Controle do Câncer do Hospital Universitário Pedro Ernesto - UERJ.

2. Nutricionista, Mestranda do Programa de Pós-Graduação em Ciências Médicas - FCM - UERJ

3. Professor Titular de Coloproctologia - FCM - UERJ.

4. Professor Adjunto do Departamento de Cirurgia Geral - FCM - UERJ.

5. Nutricionista, Mestranda do Programa de Pós-Graduação em Fisiopatologia Clínica e Experimental - FCM - UERJ.

6. Médico-Veterinário Bolsista do Laboratório de Cirurgia Experimental - FCM - UERJ.
} 


\section{Amostra}

Foram utilizados 30 ratos machos Wistar adultos, com peso inicial entre 270 e 315 gramas. Esses animais foram divididos em três grupos de estudo, com dez animais cada um: I - controle; II - irradiado; e III - irradiado, com suplementação de L-glutamina (Novartis NutritionÒ). O Grupo Controle foi mantido em condições-padrão de laboratório durante os 14 dias do experimento, enquanto os grupos II e III foram submetidos à irradiação abdominal no $8^{\circ}$. dia da experimentação. Os animais do grupo III receberam suplementação oral de glutamina durante os 14 dias do experimento. Todos os animais foram operados no $15^{\circ}$. dia, para ressecção de segmento colônico para análise estereológica.

Todos os animais tiveram livre acesso à água e ração comercial (Nuvilab-CR1Ò- (Nuvilab NutrientesÒ), durante todo o período da experimentação, e foram mantidos em gaiolas individuais, em biotério climatizado, com foto-períodos de 12 horas diárias.

\section{Irradiação abdominal}

Os animais dos grupos II e III foram imobilizados em caixas plásticas e submetidos à dose única de irradiação, de 1000 cGy, no $8^{\circ}$. dia da experimentação. A irradiação foi liberada a partir de um acelerador linear de $06 \mathrm{MeV}$ (modelo Clinac $2100 \mathrm{O}$ - VarianÒ), a uma velocidade de liberação de 240 cGy por minuto, com distância fonte-pele de $100 \mathrm{~cm}$, aplicados sobre o abdome, em um campo de 6 x $4 \mathrm{~cm}$. A dose de $1000 \mathrm{cGy}$ foi calculada a $3 \mathrm{~cm}$ da pele (normalização da dose) e liberada no sentido dorsal. Os ratos foram irradiados com o tórax, cabeça e extremidades situando-se fora da área de irradiação.

\section{Suplementação de glutamina}

Os animais do grupo III receberam suplementação de Lglutamina por via oral, durante os 14 dias da experimentação, na dose de $1 \mathrm{~g} / \mathrm{kg} /$ dia. A dose diária foi preparada em solução aquosa, em concentração média de $6 \%$, perfazendo volume final de $5 \mathrm{ml}$ e administrada por via oral, em bolus, através de um cateter nasogátrico, uma vez ao dia, sempre no mesmo horário.

\section{Ressecção dos segmentos intestinais}

Os animais foram operados sob anestesia geral com tiopental sódico (TiopentalÒ-Abbott Ò), na dose de $50 \mathrm{mg} / \mathrm{kg}$ peso, por via intraperitoneal. $\mathrm{O}$ acesso à cavidade abdominal foi feito por laparotomia mediana, com cerca de $3 \mathrm{~cm}$ de extensão.

Em seguida, pelo orifício anal, foi introduzido um cateter $20 \mathrm{G}$ (Becton-Dickinson ${ }^{\circledR}$ ) com graduação em centímetros, com o intuito de demarcar, exatamente, o local para ressecção do segmento colônico, estipulado como se situando entre 6 e 8 $\mathrm{cm}$ da margem anal.

Realizou-se, então, ressecção circunferencial de segmento de cólon com cerca de $2 \mathrm{~cm}$ de extensão, na posição previamente demarcada pelo cateter introduzido por via anal. Seguiu-se a morte dos animais, por sobredose anestésica de tiopental sódico. Procedeu-se a laparorrafia, em dois planos (peritônio-aponeurótico e pele), com suturas contínuas, utilizando-se polipropileno 2-0 (Prolene ${ }^{\circledR}-$ Ethicon $^{\circledR}$ ).

\section{Processamento histológico}

O segmento colônico foi aberto em sentido longitudinal, lavado em soro fisiológico, para retirada de detritos fecais, e distendido sobre papel filtro. A fixação foi realizada em solução de formol tamponado a $10 \%$, por um período de 24 horas, sendo o material, em seguida, desidratado em uma série crescente de álcoois e incluídos em parafina (Parafina para Histologia ${ }^{\circledR}$ Merck $^{\circledR}$ ), de acordo com as normas para análise estereológica de cortes verticais ${ }^{9}$. Em seguida, esse material foi cortado, com o auxílio de um micrótomo rotativo (Leica RM2025 ${ }^{\circledR}$, Leica Instruments ${ }^{\circledR}$ - China), obtendo-se oito cortes, com $4 \mathrm{~mm}$ cada, que foram submetidos à coloração tricrômica de Gomori, para evidenciação das diferentes camadas da parede colônica.

\section{Análise estereológica}

Os cortes histológicos foram analisados em sistema de microscópio computadorizado, composto por microscópio óptico (BH-2Ò - OlympusÒ) dotado de objetivas planas acromáticas. A ocular foi acoplada a uma câmera de vídeo (Galai ${ }^{\circledR}$ ), que transmitia as imagens a um microcomputador, com exibição das imagens em um monitor de 17 polegadas, com dot pitch 0,23 e aumento final entre 200 e 500 vezes. A análise estereológica ${ }^{10}$ foi realizada em campos aleatórios, em um total de oito campos por animal.

Sob aumento de 200 vezes, foram analisados o volume total da parede do cólon (V) e os volumes parciais da mucosa ( $\mathrm{Vv}$ $\mathrm{m}$ ), da muscular da mucosa (Vv mm), da submucosa (Vv s) e da muscular própria ( $\mathrm{V} v \mathrm{mp}$ ). Esta análise foi praticada por superposição de um sistema-teste tradicional (Figura 1) às imagens dos cortes da parede colônica. Esse sistema-teste era composto por 100 pontos. O volume total (V) da parede do cólon correspondeu ao número de pontos ocupados pela estrutura dentro do sistema-teste, e o volume parcial (Vv) das diversas camadas foi calculado pela razão entre o número de pontos da grade que incidia sobre determinada camada e o número total de pontos da grade que incidiam sobre a parede. 


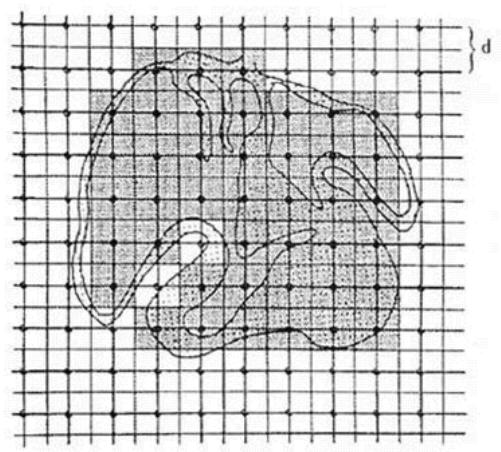

FIGURA 1 - Sistema-teste tradicional, utilizado na análise estereológica, sob aumento de 200X

Sob aumento de 500 vezes, foram analisados os volumes parciais ocupados na mucosa pelo epitélio (Vv epi) e pela lâmina própria ( $\mathrm{Vv}$ lp), assim como foi determinada a superfície epitelial (Su epi). Esta análise foi praticada por superposição de um sistema-teste tipo ciclóide, composto por 35 arcos ciclóides e 70 pontos. Os volumes parciais do epitélio e da lâmina própria foram calculados pela razão entre o número de pontos da grade que incidiam sobre cada um deles e o número total de pontos da grade (Figura 2). O número de pontos de intercessão entre os arcos ciclóide deste sistema-teste e as criptas de Lieberkühn foi utilizado para calcular a área de superfície epitelial, segundo a fórmula de Weibel (1979) ${ }^{11}$ :

$$
\text { Sv }=\frac{4 \text { I epi }}{\text { P epi . d }}
$$

Onde: $\mathrm{I}$ epi $=$ número total de intercessões; $\mathrm{P}$ epi $=$ número total de pontos da grade que incidem sobre o epitélio; e $\mathrm{d}=$ comprimento do arco ciclóide da grade utilizada.



FIGURA 2 - Sistema-teste tipo ciclóide, utilizado na análise estereológica, sob aumento de 500X.

\section{Análise estatística}

A comparação dos grupos, considerando as diversas variáveis, foi realizada por análise de variância - teste não-paramétrico de Kruskal-Wallis - e pelo pós-teste de Dunn. Os dados foram expressos em média \pm erro padrão, e, em todas as análises, um valor de $\mathrm{p}=0,05$ foi estabelecido para rejeição da hipótese nula.

\section{Aspectos éticos nos cuidados com os animais}

Este projeto de pesquisa foi aprovado pelo Comitê de Ética em Pesquisa Animal do Instituto de Biologia Roberto Alcântara Gomes, da Universidade do Estado do Rio de Janeiro.

Todos os procedimentos seguiram, rigorosamente, a regulamentação existente sobre experimentação com animais ${ }^{12}$.

\section{Resultados}

A irradiação abdominal no grupo II diminuiu significativamente o volume total da parede do cólon (V) ( $\mathrm{p}<0,01)$, quando comparado ao grupo controle (Figura 3), sem alterar os volumes parciais de cada camada histológica: mucosa (Vv m) (Figura 4A), muscular da mucosa (Vv mm) (Fig. 4B), submucosa (Vv s) (Figura 4C)e muscular própria (Vv mp) (Figura 4D). A suplementação de Lglutamina aos animais do grupo III foi capaz de manter a espessura da parede do cólon semelhante à do Grupo Controle (V) (p > $0,05)$. Entretanto, quando se analisou o volume parcial das várias camadas histológicas, observou-se um aumento do volume parcial da camada mucosa ( Vv m) (Figura 4A), quando comparado ao Grupo Controle $(\mathrm{p}<0,01)$ e ao grupo II $(\mathrm{p}<0,001)$, e uma diminuição dos volumes parciais da muscular da mucosa $\left(\mathrm{Vv}_{\mathrm{v}}\right.$ $\mathrm{mm}$ ) (Figura 4B), submucosa (Vv s) (Figura 4C) e muscular própria (Vv mp) (Figura 4D), em comparação com os mesmos grupos. 
Volume Total da Parede do Cólon

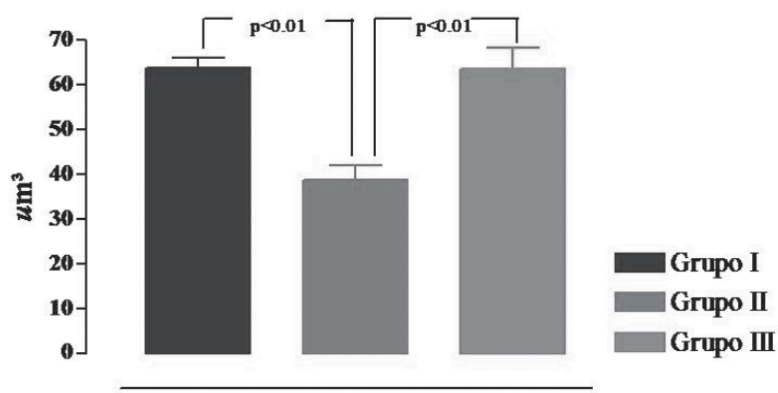

FIGURA 3 - Variações do volume total da parede do cólon entre os grupos controle (I), irradiado (II) e irradiado com suplementação de L-glutamina (III)

A

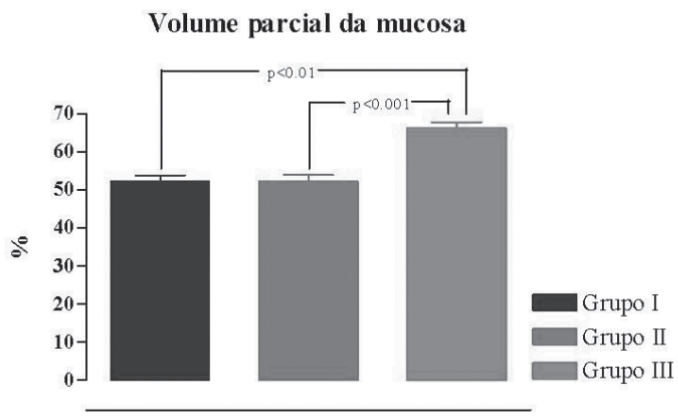

Volume parcial da submucosa

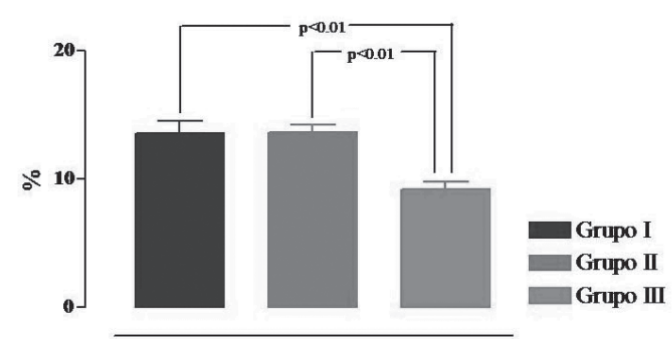

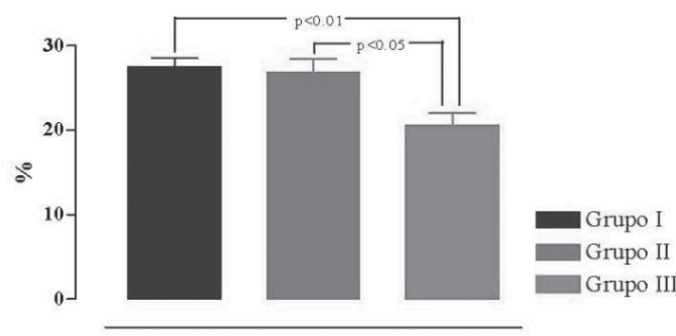

Volume parcial da muscular própria

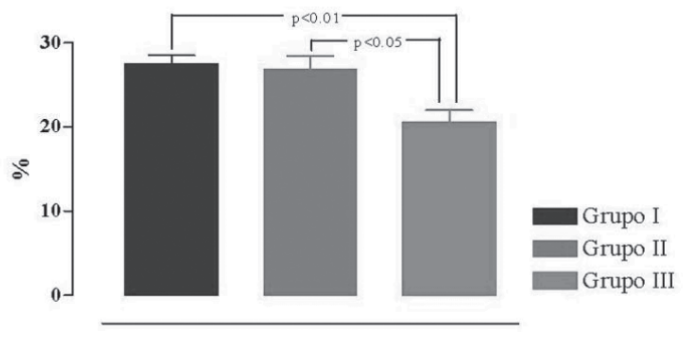

FIGURA 4 - Variações dos volumes parciais das camadas mucosa (A), muscular da mucosa (B), submucosa (C) e muscular própria (D), entre os grupos controle (I), irradiado (II) e irradiado com suplementação de L-glutamina (III)

Focalizando apenas a camada mucosa, observou-se que o volume parcial do epitélio (Vv epi) tornou-se significativamente diminuído no grupo II ( $\mathrm{p}<0,001)$, cujos animais sofreram irradiação, quando comparado ao Grupo Controle (Figura 5A). Inversamente, o volume parcial da lâmina própria (Vv lp) aumentou no grupo II ( $\mathrm{p}<0,001)$, quando comparado ao Grupo Controle (Figura 5B). O grupo III, cujos animais foram irradiados e receberam suplementação oral de L-glutamina, apresentou volumes parciais de epitélio
( Vv epi) e lâmina própria ( Vv lp), semelhantes ao Grupo Controle $(\mathrm{p}>0,05)$ (Figura 5A e B).

No que se refere à superfície epitelial (Su epi), no grupo II ela se apresentou significativamente diminuída, quando comparado ao Grupo Controle ( $\mathrm{p}<0,001)$. Conquanto o grupo III tenha apresentado uma superfície epitelial $(\mathrm{Su}$ epi) maior do que o grupo II, ainda assim, ela foi significativamente menor que a do Grupo Controle $(\mathrm{p}<0,05)$ (Figura 5C). 
Volume parcial do epitélio na mucosa

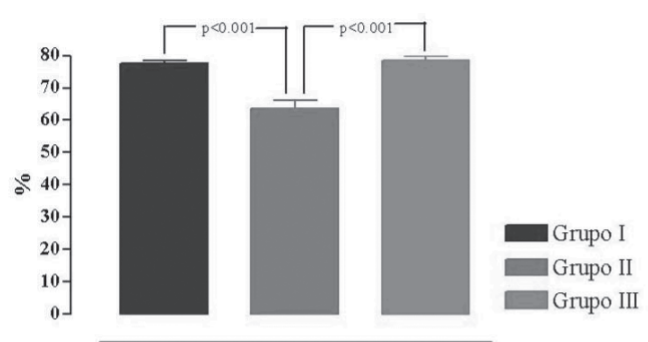

Volume parcial da lâmina própria na mucosa

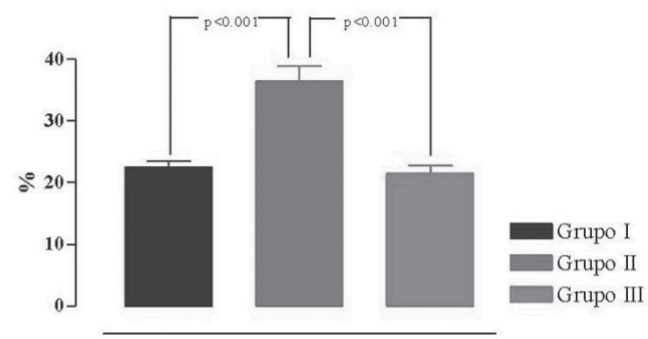

Superficie epitelial da mucosa

C

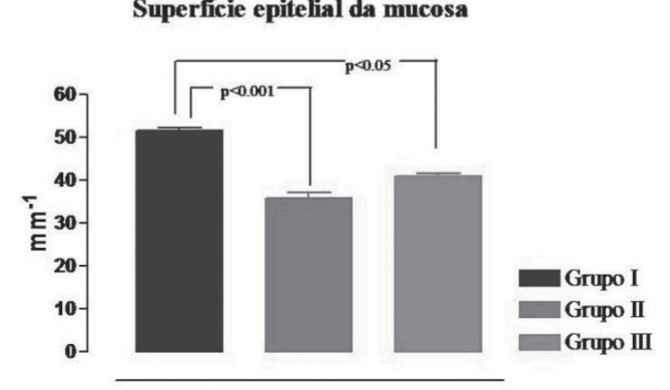

FIGURA 5 - Variações dos volumes parciais do epitélio da mucosa (A), da lâmina própria da mucosa (B) e da superfície epitelial da mucosa do cólon (C), entre os grupos controle (I), irradiado (II) e irradiado com suplementação de L-glutamina (III)

Na tabela 1, pode ser observado um resumo dos dados numéricos encontrados para cada variável em cada grupo de estudo.

Os resultados estão expressos em média \pm erro padrão.

TABELA 1 - Médias \pm erro padrão de todas as variáveis analisadas por grupo de estudo

\begin{tabular}{ccccccccc}
\hline Grupos & $\begin{array}{c}\mathbf{V} \\
\left(? \mathbf{m}^{\mathbf{3}}\right)\end{array}$ & $\begin{array}{c}\mathbf{V v} \mathbf{m} \\
\mathbf{( \% )}\end{array}$ & $\begin{array}{c}\mathbf{V v} \mathbf{m m} \\
\mathbf{( \% )}\end{array}$ & $\begin{array}{c}\text { Vv s } \\
\mathbf{( \% )}\end{array}$ & $\begin{array}{c}\mathbf{V v ~ m p} \\
(\mathbf{\%})\end{array}$ & $\begin{array}{c}\text { Vv epi } \\
(\mathbf{\%})\end{array}$ & $\begin{array}{c}\text { Vv lp } \\
(\mathbf{\%})\end{array}$ & $\begin{array}{c}\text { Su epi } \\
\left(\mathbf{m m}^{-1}\right)\end{array}$ \\
\hline \hline Controle (I) & $63,93 ?$ & $52,23 ?$ & $6,58 ?$ & $13,63 ?$ & $27,56 ?$ & $77,51 ?$ & $22,49 ?$ & $51,47 ?$ \\
& 1,91 & 1,41 & 0,25 & 0,86 & 0,89 & 0,85 & 0,85 & 0,72 \\
Irradiado (II) & $38,84 ?$ & $52,20 ?$ & $7,22 ?$ & $13,64 ?$ & $26,93 ?$ & $63,63 ?$ & $36,37 ?$ & $35,78 ?$ \\
& 3,13 & 1,66 & 0,25 & 0,63 & 1,58 & 2,44 & 2,44 & 1,32 \\
Irradiado + & $63,56 ?$ & $66,11 ?$ & $4,18 ?$ & $9,21 ?$ & $20,50 ?$ & $78,54 ?$ & $21,46 ?$ & $40,9 ?$ \\
suplementação de & 4,66 & 1,67 & 0,32 & 0,63 & 1,38 & 1,26 & 1,26 & 0,66 \\
L-glutamina (III) & & & & & & & & \\
\hline
\end{tabular}

V - Volume total da parede colônica, Vv m - volume parcial da mucosa, Vv mm - volume parcial da muscular da mucosa, Vv s - volume parcial da submucosa, Vv mp - volume parcial da muscular própria, Vv epi - volume parcial do epitélio da mucosa, Vv lp - volume parcial da lâmina própria da mucosa e Su epi - superfície epitelial da mucosa

\section{Discussão}

A glutamina é o aminoácido mais abundante no sangue e no pool de aminoácidos corporais ${ }^{13}$. Seu metabolismo intracelular é regulado, principalmente, por duas enzimas: a glutaminase, que catalisa a hidrólise da glutamina a glutamato, e a glutaminosintetase, que catalisa a síntese de glutamina, a partir de glutamato e amônia ${ }^{14}$. As células epiteliais da mucosa intestinal apresentam alta concentração de glutaminase, compatível com as altas taxas de captação e consumo de glutamina . Todo o trato gastrointestinal extrai ao redor de $20 \%$ da glutamina circulante no período pós-absortivo, e mais de $90 \%$ de sua extração pelo intestino delgado ocorre nas células da mucosa ${ }^{13}$.

O emprego da radioterapia tem como objetivo a erradicação ou o controle do crescimento de tumores, devendo, ao mesmo tempo, poupar os tecidos normais contíguos de seqüelas ${ }^{1}$, porém, a radiação ionizante sobre o intestino interfere nos processos de divisão celular, determinando diminuição do número de mitoses e da população celular na cripta.

Os colonócitos, foco de nosso estudo, utilizam preferencialmente ácidos graxos de cadeia curta como fonte energética, 
particularmente ácidos acético, propiônico e butírico. Estes ácidos graxos são formados pela degradação bacteriana das fibras alimentares do conteúdo fecal no cólon. Ainda que a glutamina se constitua em um substrato secundário para a mucosa colônica, ${ }^{16}$ o nosso objetivo em testá-la para a possível recuperação do cólon, e não as fibras, se deveu à hipótese de que a ela poderia ser utilizada eficientemente no cólon, dada a demanda aumentada de substratos para recuperação celular. Ademais, devido aos efeitos colaterais comuns da enterite actínica, como náuseas, cólicas e diarréia, a tolerância gastrointestinal à glutamina seria melhor, já que a mesma não produz efeitos colaterais no seu processo de digestão e absorção.

São muito escassos os estudos existentes na literatura acerca da ação da glutamina no cólon irradiado. Campos e cols. (1994) avaliaram o efeito da irradiação no cólon, mas por estudo histopatológico ${ }^{1}$. Nosso estudo, alternativamente, buscou, por análise estereológica, quantificar numericamente as estruturas analisadas, não existindo, pois, ao menos no momento, parâmetros para a sua comparação direta.

Os nossos resultados mostraram que a irradiação abdominal produziu uma destruição considerável na parede colônica, porém, a suplementação de glutamina nos animais foi capaz de manter esse volume similar ao normal, primordialmente a partir de hipertrofia da camada mucosa. Estes achados poderiam ser atribuídos à utilização da glutamina pela mucosa colônica, considerando que, em estudos in vitro, os colonócitos também metabolizam glutamina em detrimento da glicose, pela atividade local de glutaminase ${ }^{15}$. Além disso, a glutamina foi capaz de aumentar o volume do epitélio da mucosa dos animais irradiados, condizente com o achado de outros autores, mas no que se refere ao epitélio do intestino delgado ${ }^{17}$.

Observamos que a suplementação de glutamina não foi capaz de melhorar significativamente a superfície epitelial da mucosa, e isto pode se dever ao fato de que a velocidade de renovação celular no cólon é mais lenta, quando comparada ao intestino delgado e, sete dias após a irradiação, o epitélio ainda se encontra bastante desordenado, de modo que as criptas intestinais, à microscopia eletrônica, se encontravam mais espaçadas e com menor espessura, como já descrito por outros autores . Além disso, já se determinou que dietas especiais não evitam a enterite actínica, mas facilitam a recuperação da mucosa, que se torna mais evidente, com o passar dos dias ${ }^{18}$.

Os dados que obtivemos da análise da parede do cólon irradiado estão em concordância com o resultado de outras pesquisas similares que focalizaram o intestino delgado irradiado ${ }^{1,7,8}$. Porém, mais estudos são necessários no que se refere a dosagens utilizadas de glutamina, período em que ela deve ser mantida (anterior e/ou posterior à irradiação), bem como suplementação de outros aminoácidos, dentre outras variáveis. Ademais, conquanto a estereologia permita quantificar numericamente as estruturas analisadas, a avaliação histopatológica complementa-a, qualitativamente.

\section{Conclusão}

Nossos resultados sugerem que a suplementação de glutamina no período anterior e posterior à irradiação, auxilia a reparação da parede colônica de ratos, favorecendo a sua recuperação no período pós-irradiação.

\section{Referências}

1. Campos FG, Mucerino DR, Waitzberg DL, Logulo AF, El Ibhahim R, Nadalin W, Habr-Gama A. Efeitos protetores da glutamina e dieta elementar na enterocolite actínica aguda: avaliação histológica. Rev Ass Med Bras 1994; 40:143-9.

2. Berthrong M, Fajardo LF. Radiation injury in surgical pathology. Part II. Alimentary tract. Am J Surg Pathol 1981; 5:153-78.

3. Marks G, Mohiudden M. The surgical management of the radiation-injured intestine. Surg Clin North Am 1983; 63:81-96.

4. Turtel PS, Shike M. Doenças do Intestino Delgado. In: Shils ME, Olson JA, Shike M, Ross AC, editores. Tratado de Nutrição Moderna na Saúde e na Doença. 9a ed. Barueri: Manole; 2003. p. 1231-41.

5. Newsholme P. Why is L-glutamine metabolism important to cells of immune system in healthy, postinjury, surgery or infection? J Nutr 2001; 131(Suppl): 2515S-22S.

6. Schloerb PR. Immune-enhancing diets: products, components and their rationales. J Parenter Enter Nutr 2001; 25:3-7.

7. Klimberg VS, Souba WW, Dolson DJ, Salloum RM, Hautamaki RD, Plumley DA, Mendenhall WM, Bova FJ, Khan SR, Hecket RL, Bland KI, Copeland EM. Prophylactic glutamine protects the intestinal mucosa from radiation injury. Cancer 1990; 66:62-8.

8. Campos FG, Waitzberg DL, Mucerino DR, Gonçalves EL, Logulo AF, Habr-Gama A, Rombeau JL. Protective effects of glutamine enriched diets on acute actinic enteritis. Nutr Hosp 1996; 11:167-77.

9. Baddeley AJ, Gundersen HJG, Cruz-Orive LM. Estimation of surface area from vertical sections. J Microsc 1986; 142:259-76.

10. Mandarim-de-Lacerda CA. Stereological tools in biomedical research. An Acad Bras Cienc 2003; 75:469-86.

11. Weibel ER. Stereological Methods. Practical methods for biological morphometry. Vol 1. London: Academic Press; 1979.

12. Brasil, Lei Federal n ${ }^{\circ}$. 6638. Princípios Éticos na Experimentação Animal, 1979.

13. Souba WW, Herskowitz K, Austgenm TR, Chen MK, Salloum RM, Glutamine nutrition: theoretical considerations and therapeutic impact. J Parent Enter Nutr 1990; 14:37-42.

14. Souba WW, Smith RJ, Wilmore DW. Glutamine metabolism by the intestinal tract. J Parent Enter Nutr 1985; 9:608-16.

15. Pinkus LM, Windmueller HG. Phosphate-dependent glutaminase of small intestine: localization and role in glutamine metabolism. Arch Biochem Biophys 1977; 182:106-17.

16. Roedger WEW. Utilization of nutrients by isolated epithelial cells of the rat colon. Gastroenterology 1982; 83:424-9.

17. Murnin M, Kumar A, Li GD, Brown M, Sumpio BE, Basson MD. Effects of glutamine isomers on human (Caco-2) intestinal 
epithelial proliferation, strain-responsiveness, and differentiation. J Gastrointest Surg 2000; 4: 435-42.
18. Bounous G, Tahan WT, Shuster J, Gold P. The use of elemental diet during abdominal radiation. Clin Res 1973;21:1066 [Resumo].

Diestel CF, Lopes-Paulo F, Marques RG, Horst NL, Caetano CER. Effect of oral supplement of l-glutamine in colonic wall of rats subjected to abdominal irradiation. Acta Cir Bras [serial on line] Available from: URL: htt://www.scielo.br/acb.

ABSTRACT - Purpose: To evaluate the structural alterations of the irradiated colonic wall in rats, verifying if L-glutamine supplementation is able to prevent them. Methods: We used 30 male adult Wistar rats, divided into three groups: I - control, II irradiated, and III - irradiated with L-glutamine supplementation during the 14 days of the study. Control group was maintained in laboratory standard conditions while groups II and three were submitted to abdominal radiation with an only dose of 1000 cGy in the $8^{\text {th }}$ day of experimentation. All the animals were submitted to laparotomy in the $15^{\text {th }}$ day for resection of the colonic segment for stereological analysis. Results: Group II presented total volume of colonic wall significantly smaller than control group without altering the partial volumes of each layer. Compared to groups II and III, group III exhibited maintenance of total volume of colonic wall, nearing control group. Compared to control group, animals of group III exhibited maintenance of epithelial partial volume without altering significantly epithelial surface. Conclusion: It is suggested that L-glutamine supplementation can be of benefit in the irradiated colonic wall in rats.

KEYWORDS: L-glutamine. Abdominal radiation. Colonic wall. Colon. Mucosa.

Correspondência:

Cristina Fajardo Diestel

Rua Luís Barbosa n. ${ }^{\circ} 28$ apto $104-$ Vila Isabel

20560-010 - Rio de Janeiro -RJ

cdiestel@ terra.com.br

Conflito de interesse - nenhum

Fonte de financiamento - nenhuma 